\title{
Benign skin disease with pustules in the newborn*
}

\author{
Flávia Pereira Reginatto ${ }^{1}$ \\ Tania Ferreira Cestari ${ }^{1}$
}

Damie De Villa ${ }^{2}$

DOI: http:/ / dx.doi.org/10.1590/abd1806-4841.20164285

\begin{abstract}
The neonatal period comprises the first four weeks of life. It is a period of adaptation where the skin often presents several changes: transient lesions, resulting from a physiological response, others as a consequence of transient diseases and some as markers of severe disorders. The presence of pustules in the skin of the newborn is always a reason for the family and for the assisting doctor to be worried, since the newborn is especially vulnerable to bacterial, viral or fungal infection. However, the majority of neonatal skin pustules is not infectious, comprising the benign neonatal pustulosis. Benign neonatal pustuloses are a group of clinical disease characterized by pustular eruptions in which a contagious agent is not responsible for its etiology. The most common ones are erythema toxicum neonatorum, the transient neonatal pustular melanosis and the benign cephalic pustulosis. These dermatoses are usually benign, asymptomatic and self-limited. It is important that the dermatologist and the neonatologist can identify benign and transient lesions, those caused by genodermatoses, and especially differentiate between neonates with systemic involvement from those with benign skin lesions, avoiding unnecessary diagnostic tests and worries.
\end{abstract}

Keywords: infant, newborn; Infant, newborn, diseases; Skin diseases; Neonatology; Skin abnormalities; Skin manifestations

\section{INTRODUCTION}

The neonatal period extends from birth to the first four weeks of life. ${ }^{1}$ It is a time of adaptation where the newborn usually has various dermatological findings: temporary lesions, some as a result of a physiological response or transient diseases, and others as markers of serious diseases. ${ }^{2-4}$ The presence of pustules or vesico-pustular lesion in newborns is always motive of concern to the family and to the attending physician, since at this age children are especially vulnerable to bacterial, viral or fungal infections. ${ }^{5}$ Sometimes these lesions represent a diagnostic challenge because they may be due to a number of diseases with variable prognostics, so it is important to differentiate between benign and transient pustular eruptions from serious cases requiring hospitalization. ${ }^{6}$
Benign neonatal pustulosis (BNP) are a set of clinical conditions characterized by transient pustular rash on the newborn skin. These are thus designated because they are asymptomatic and self-limiting. They include sterile pustulosis, such as erythema toxicum neonatorum (ETN) and transient neonatal pustular melanosis (TNPM), in which no infectious agent can be implied in its etiology; and benign cephalic pustulosis (BCP) which, according to some authors, may be related to the presence of Malassezia. ${ }^{5}$ Other benign dermatological findings that may present pustules during the neonatal period are: miliaria pustulosa; miliaria rubra (MR), which under occlusion areas may present vesicles with pustular appearance; infantile acropustulosis and eosinophilic folliculitis.

Received on 04.12.2014.

Approved by the Advisory Board and accepted for publication on 03.03.2015.

Study performed at Programa de Pós-Graduação em Saúde da Criança e Adolescente da Universidade Federal do Rio Grande do Sul - Hospital de Clínicas de Porto Alegre (UFRGS-HCPA), Complexo Hospitalar Santa Casa de Misericórdia de Porto Alegre e Hospital Fêmina - Grupo Hospitalar Conceição - Porto Alegre (RS), Brazil.

Financial Support: Incentive Fund for Research and Development of HCPA - FIPE.

Conflicts of Interest: None.

Universidade Federal do Rio Grande do Sul (UFRGS) - Porto Alegre (RS), Brazil

Santa Casa de Misericórdia de Porto Alegre - Porto Alegre (RS), Brazil.

(C)2016 by Anais Brasileiros de Dermatologia 


\section{NEWBORN SKIN}

Newborn (NB) skin is often characterized as delicate and fragile. ${ }^{7}$ Functional differences between the newborn and adult skin may be attributed to differences in skin microstructure. ${ }^{8}$ Besides being $40-60 \%$ thinner than adult skin, newborn skin has a higher transepidermal water loss and delay in sudoral response, believed to be due to the immaturity of the sympathetic system. ${ }^{2}$ In neonatal period the skin plays an important role as a regulator of temperature and as a barrier against skin infections. The cutis of the newborn is also more likely to develop certain dermatoses such as irritant contact dermatitis, when compared with adult skin. ${ }^{3,7}$

The barrier function of human skin begins to develop in utero with the stratification of the epidermis during the first trimester of pregnancy, and it is believed to be complete by 34 weeks of gestation. 3,9 The formation of vernix caseosa in the third quarter contributes to the final stage of maturation of the epidermal barrier. ${ }^{3}$ Despite the epidermal barrier function by baseline permeability being established at birth, increased risk of infections, dermatitis and percutaneous absorption of toxic agents can indicate an incomplete maturation in early neonatal period. ${ }^{10}$

\section{NEONATAL SKIN PUSTULES}

Dermatoses that can present pustules during the neonatal period can be divided into two major groups: infectious and non-infectious or sterile. ${ }^{2}$ It is important that the neonatologist and the dermatologist know how to identify benign and transient lesions and, mainly, to differentiate newborns with systemic involvement from those in which the dermatosis is restricted to skin. ${ }^{6,11}$

Table 1 lists the major skin diseases in the neonatal period that presents pustules and its usual pathogens.

In most cases, BNP are transient, and caused by environmental factors, or occur as a physiological skin response. ${ }^{6}$ Diagnosis of BNP is clinical, but in atypical cases it may be necessary to use methods of investigation with complementary tests, preferably non-invasive, and that are useful in differentiating benign and transient pustules from serious cases requiring hospitalization.

Facing the newborn with pustules, maternal diseases should be discarded, such as vulvovaginal candidiasis, genital herpes, syphilis and scabies. Dermatological examination of the newborn should evaluate the distribution and morphology of lesions, the time when the skin lesions appeared and how they evolved. It is important to discard the signs of systemic disease in newborns as fever or hepatosplenomegaly. Realization of the direct examination of the lesion scraping and staining by Gram method can identify the presence of Gram positive bacteria such as Staphylococcus and Streptococcus, and less frequently, Gram negative; moreover, it helps to identify the cellular composition of the inflammatory infiltrate when present. ${ }^{12}$ Direct examination of scales clarified with potassium hydroxide allows identifying fungal elements,

TABle 1: Neonatal dermatoses that occur with pustules

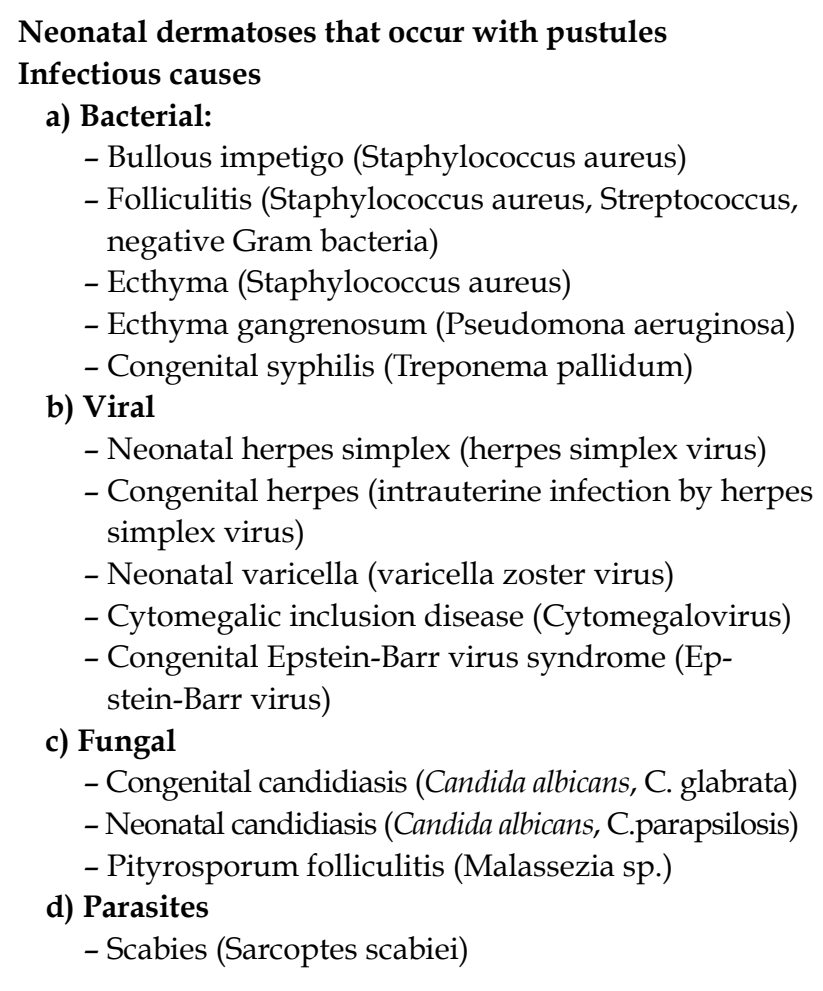

Non-infectious causes

a) Miliaria pustulosa or profunda

b) Transient benign neonatal pustules

- Erythema toxicum neonatorum (ETN)

- Transient neonatal pustular melanosis (TNPM)

c) Infantile acropustulosis

d) Benign cephalic pustulosis (BCP) including neonatal acne

f) Pigmentary incontinence

g) Neonatal Langerhans cell histiocytosis

h) Transient myeloproliferative disease in patients with Down syndrome

i) Eosinophilic pustular folliculitis in childhood

j) Eosinophilic papular-pustular rash of Hyper IgE syndrome

k) Eeosinophilic pustulosis

1) Neonatal Behcet's disease

m) Neonatal pustular psoriasis 
which is useful for the detection of dermatophytosis and other infections caused by Malassezia or Candida spp. The cytodiagnosis of Tzank informs about the presence of multinucleated cells and inclusion bodies suggestive of herpes infection. Direct examination of lesion scraping can identify mites such as Sarcoptes scabiei. These procedures are generally sufficient to identify an infectious process; in the case of persistent doubt, syphilis serology, culture of pustules' contents or skin biopsy should be performed. ${ }^{5}$

\section{BENIGN SKIN PUSTULOSES IN NEONA- TAL PERIOD}

The main lesions described as typical of the neonatal period include erythema toxicum neonatorum (ETN), transient neonatal pustular melanosis (TNPM) and benign cephalic pustulosis (BCP). These are a benign, self-limited, asymptomatic skin diseases that occur in the first days of life. In rare cases, miliaria rubra can present pustules, mainly in the areas of friction, or even progress to miliaria pustulosa in the skin of the newborn.

\section{Erythema toxicum neonatorum:}

Erythema toxicum neonatorum (ETN) is considered an inflammatory reaction of the skin and is also called allergic neonatal erythema or neonatal erythema. ${ }^{13}$ It is characterized by erythematous papules and sterile pustules surrounded by an erythematous halo measuring approximately 1 to $2 \mathrm{~cm}$ affecting the trunk, the extremities and face of the NB (Figures 1 and 2). Lesions usually appear on the second day of life and regress in 5 to 14 days, but atypical setting may have a later onset. ${ }^{14-16}$

ETN occurs in about $16 \%$ of NB. ${ }^{17}$ In a multicenter study with 2878 newborns, performed in a capital in the Southern region of Brazil, ETN was observed in $21 \%$ of the NB. ${ }^{18}$

ETN is most commonly observed in male newborns. ${ }^{13,18}$ It also tends to be more prevalent in fullterm compared with preterm newborns; in NB who are born during the spring months; in NB with good health - characterized by the Apgar score in the first minute of life greater than 8 , and in the children born of mothers with no gestational risk factors. ${ }^{18,19}$
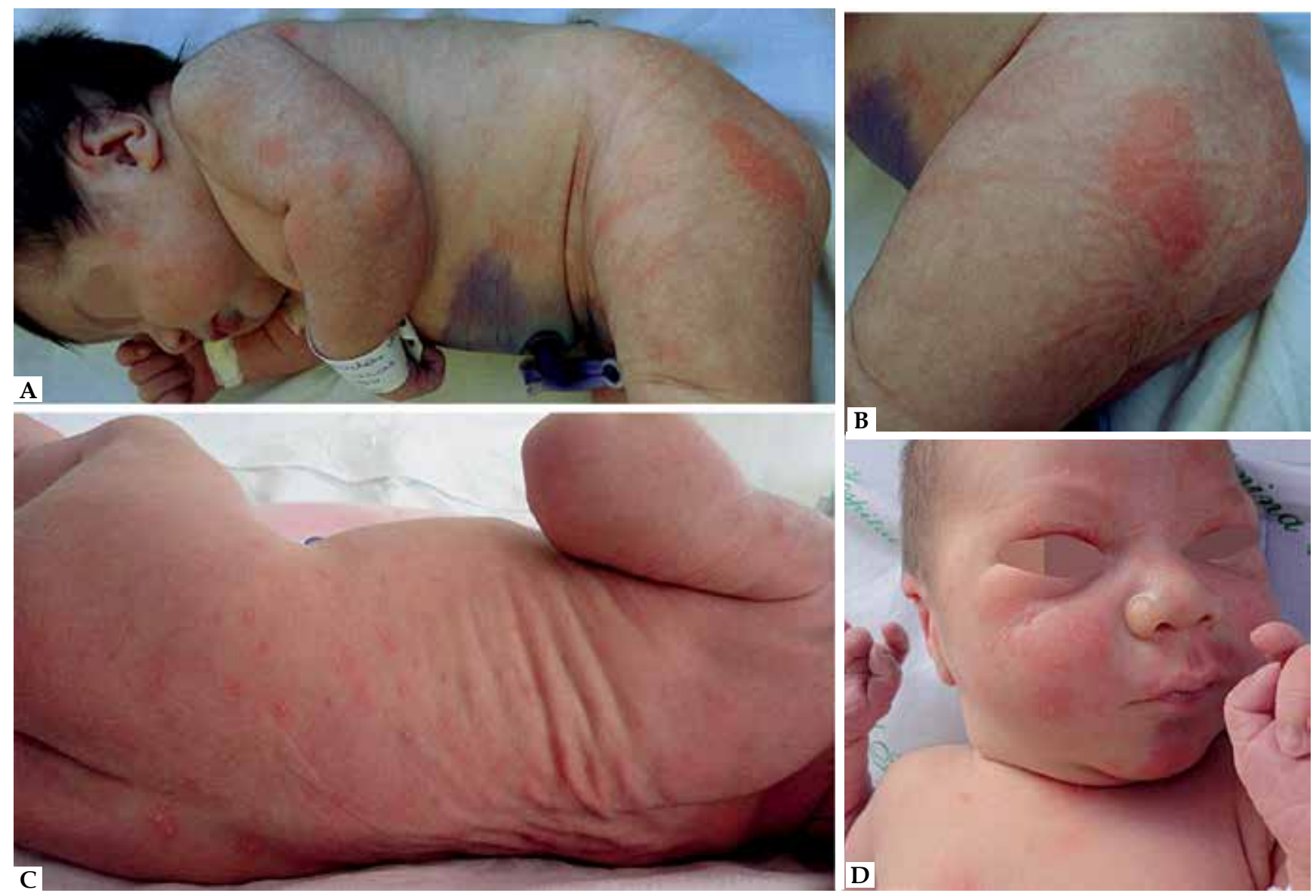

FIGURE 1: Erythema toxic neonatorum. A: ETN lesions on the trunk and limbs of a full-term newborn. B: Detail of the lesion: pustule surrounded by an erythematous halo of appoximatelly $2 \mathrm{~cm}$ on the thigh side. C: Pustules affecting the back of the upper limbs D: Involvement of the face 
ETN was reported by some authors as being more frequent in newborns delivered by cesarean, while other authors affirm that it is more common in vaginal delivery, and a study conducted in the Southern region of Brazil observed no difference between types of delivery. ${ }^{13,18,20,21}$ It was also described as being more prevalent in children of multiparous mothers by some authors and with no difference between the type of delivery by others. ${ }^{18,21}$

There are cases of ETN predominantly pustular, but they are uncommon. In such cases there is a tendency to use some synonyms, such as transient neonatal pustulosis, pustular ETN and atypical ETN (Figure 2). 22,23

The cytological examination of pustule reveals the presence of numerous eosinophils. Histopathological changes include subcorneal pustule; dense inflammatory infiltrate mainly near the hair follicles, comprising numerous dendritic cells, eosinophils, neutrophils and macrophages. High expression of E-selectin molecule was demonstrated, as well as pro-inflammatory cytokines IL-1 $\alpha$ and IL-1 $\beta$, IL-8 chemokine and eotaxin. ${ }^{24,25}$
Although the etiology of ETN is still considered unknown, some studies have shown activation of the immune response in the lesions, suggesting that this setting may correspond to an inflammatory reaction of the skin to microbial colonization occured at birth. ${ }^{17,26,27}$ It was also shown the activation of the immune system through the identification of inflammatory mediators aquaporin-1 (AQP1), aquaporin-3 (AQP3), psoriasin and nitric oxide synthase (NOS) by immunohistochemistry in ETN lesions. ${ }^{28}$

Among the children with allergy manifestation during the first two years, $84.2 \%$ had ETN or low skin $\mathrm{pH}$ at birth, and atopic dermatitis was diagnosed in $85.7 \%$ of the NB who presented the pustulosis. ${ }^{29}$ The description of ETN in siblings raises the possibility that common environmental and genetic factors may also influence its development. ${ }^{23}$

\section{Transient neonatal pustular melanosis:}

Transient neonatal pustular melanosis (TNPM) is characterized by flaccid and superficial pustules, which disrupt easily forming a collarette of scales, and
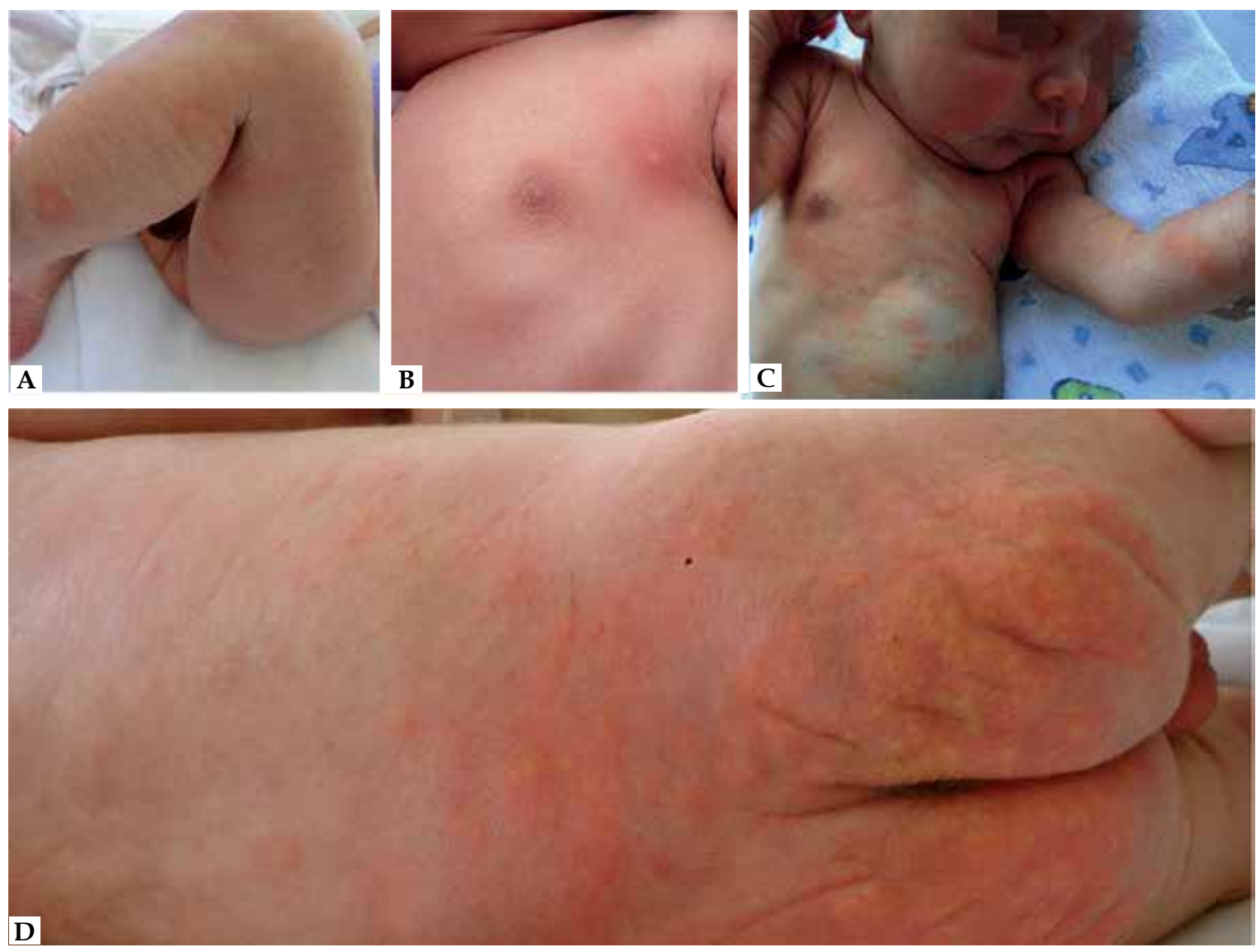

Figure 2:

Erythema toxicum neonato$\operatorname{rum}(\mathrm{ETN})$.

$A$ and B: Lesion characteristic of ETN: pustule surrounded by an erythematous halo.

C and D: ETN pustulosis 
thus progressing to residual hyperpigmented macules of residual character (Figures 3 and 4 ) ${ }^{30}$ All areas of the body can be affected, including palms, soles and genitalia. Lesions are usually present at birth. (Figure 3)

TNPM is more prevalent in African-American $\mathrm{NB}$, occurring in about $5 \%$ of black NB and in only $0.2 \%$ of whites. ${ }^{31}$ A study conducted in maternity hospitals in Porto Alegre showed a prevalence of $3.4 \% .{ }^{18}$

TNPM affects both sexes with the same frequency. ${ }^{6,18}$ Cytological examination of the pustules show polymorphonuclear neutrophils. So far the etiological mechanisms of TNPM are not clear. It is likely that TNPM corresponds to a variance of ETN, as there are described cases in which the same NB presents clinical and histological findings of ETN and TNPM, and other cases in which clinical findings are characteristic of TNPM, but the histology shows findings characteristic

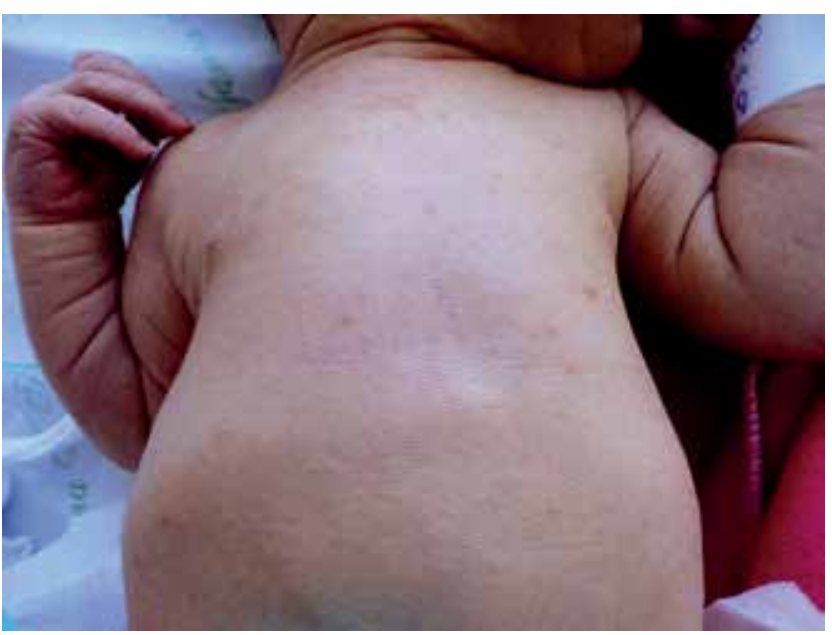

Figure 3: Transient neonatal pustular melanosis. Hyperchromic macules present at birth

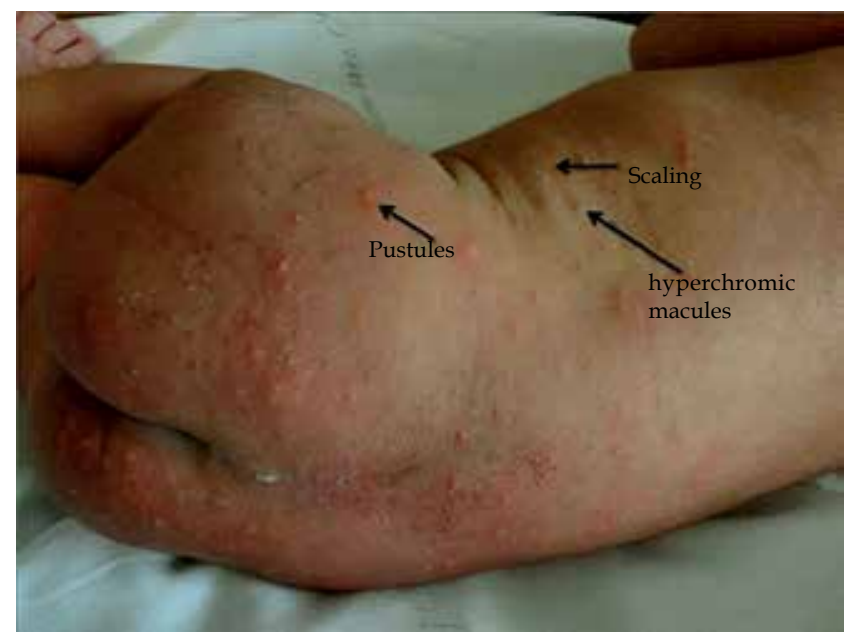

FIGURE 4: Transient neonatal pustular melanosis (TNPM). Presence of pustules, hyperchromic macules and scaling in newborn with 24 hours of life of ETN. ${ }^{5,14}$ In addition, it is often difficult to establish a clear distinction between the two diseases, which has raised the idea that the same unknown trigger factor would cause initially different settings when it affects the skin of the fetus (TNPM) or of the NB (ETN). Because of the difficulty in differentiating the clinical and histopathological limit of both diseases, Ferrandiz et al proposed the term sterile transient neonatal pustulosis to unify ETN and TNPM. ${ }^{5}$

\section{Benign cephalic pustulosis:}

Benign cephalic pustulosis (BCP) was described in 1991 by Aractingi. It is a relatively common benign disease with prevalence estimated between $10 \%$ and $66 \%$ in the neonatal period, and it presents a benign and self-limited course. ${ }^{5,12,32}$ This dermatosis is characterized by multiple inflammatory papules and pustules on the face and scalp that usually begin between 5 days and 3 weeks of age (Figure 5 and 6). ${ }^{2}$ The direct examination of smear of pustule, clarified with potassium hydroxide, can show mycotic elements and culture can show Malassezia synpodialis, and less frequently M. furfur or M. globosa. ${ }^{12}$ A study conducted in Turkey with 104 newborns showed that colonization by Malassezia increases significantly with days of life of the NB with $\mathrm{BCP}(5 \%$ in the first week, $30 \%$ between the second and fourth week of life). However, this correlation between neonatal cephalic pustulosis and colonization by Malassezia is not well established. ${ }^{33}$

\section{Miliaria:}

Miliaria is a common condition in newborns and is more observed during the summer months, febrile periods or in NB with excess clothing. ${ }^{2}$ The most common is miliaria crystalline (MC), which is characterized by small vesicles over healthy skin, especially

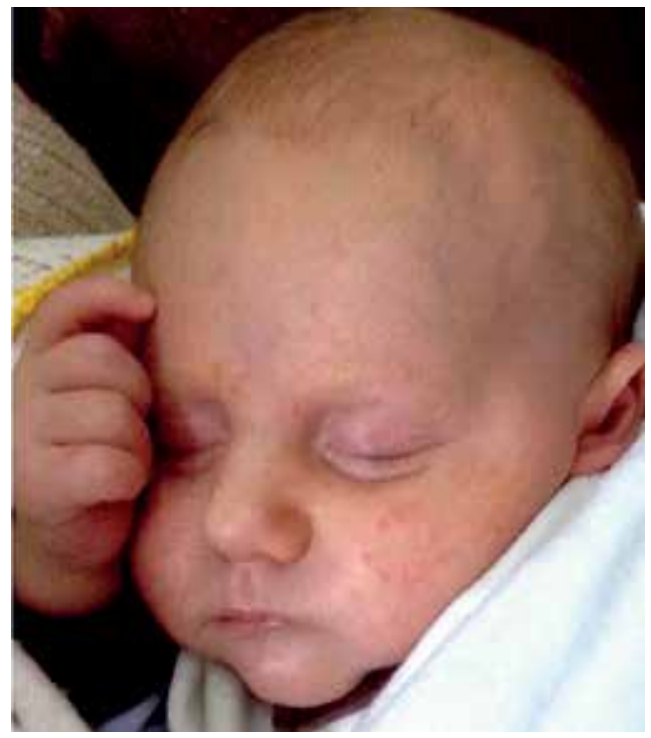

Figure 5:

Benign cephalic pustulosis. Erythematous papules and pustules on the face of a newborn with three weeks of life 
face, neck and trunk (Figures 7 and 8). Miliaria rubra (MR) is caused by obstruction of eccrine sweat gland duct, slightly deeper than MC, with sweat retention

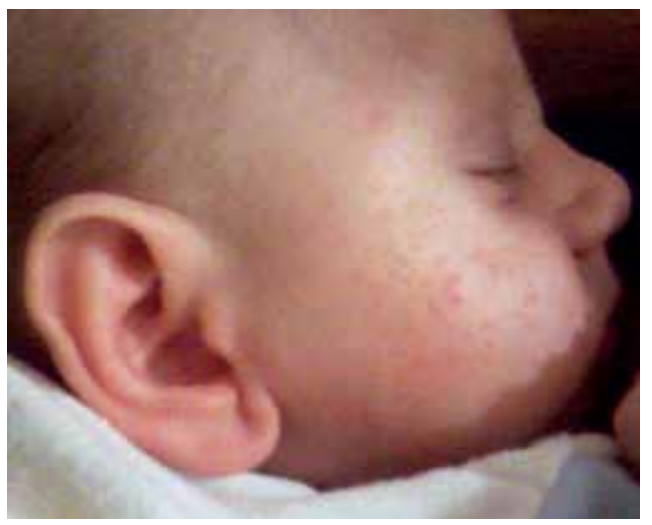

Figure 6: Benign cephalic pustulosis (BCP). Erythematous papules and pustules on

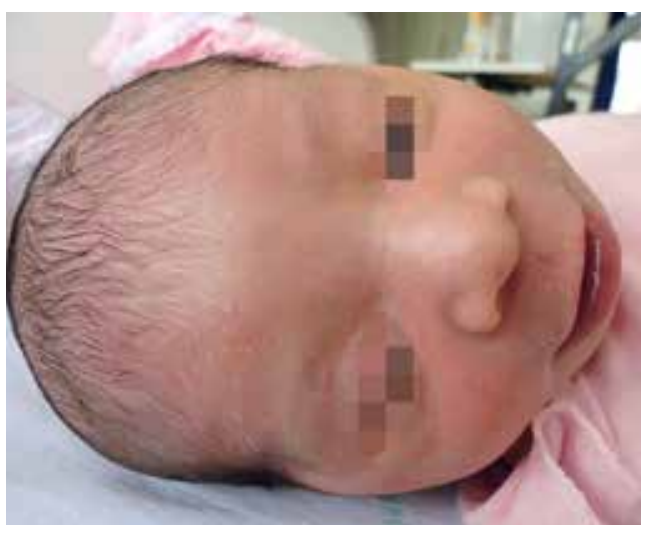
the face

Figure 7: Miliaria crystallina. Microvesicles affecting the forehead of a newborn in the epidermis. MR is characterized by numerous erythematous papules or grouped pruritic papular vesicles, and when they are in areas under occlusion they can have a pustular aspect (Figure 8). ${ }^{11}$ Rarely MR can progress to deep miliaria or miliaria pustulosa (MP), caused by a deeper obstruction of the eccrine gland duct and characterized by the presence of pustules (Figure 8). ${ }^{32} \mathrm{MR}$ lesions usually begin after the second week of life and predominate in the trunk and in intertriginous areas where occlusion by clothing is accentuated. In hot environments lesions on the scalp, face and neck may appear. ${ }^{5}$ It is the only pustular eruption of NB where most cells observed in cytology are lymphocytes. ${ }^{5}$ A recent analytical study of pustular eruptions in newborns showed that Staphylococcus aureus was isolated in $29.4 \%$ of cases of MP. ${ }^{6}$ Diagnosis of miliaria is clinical. Lesions may resolve without intervention, but there is a proven benefit in lowering the environment temperature, thus reducing the NB transpiration. $^{32}$

\section{UNUSUAL CAUSES OF NEONATAL PUS- TULOSIS}

The differential diagnosis of neonatal benign pustulosis (NBP) is performed with the infantile acropustulosis (IA), eosinophilic pustular folliculitis (EPF) and scabies, which are dermatosis that present as pruritic vesicopustules, most common in infants, but that have been reported in the neonatal period. ${ }^{5}$
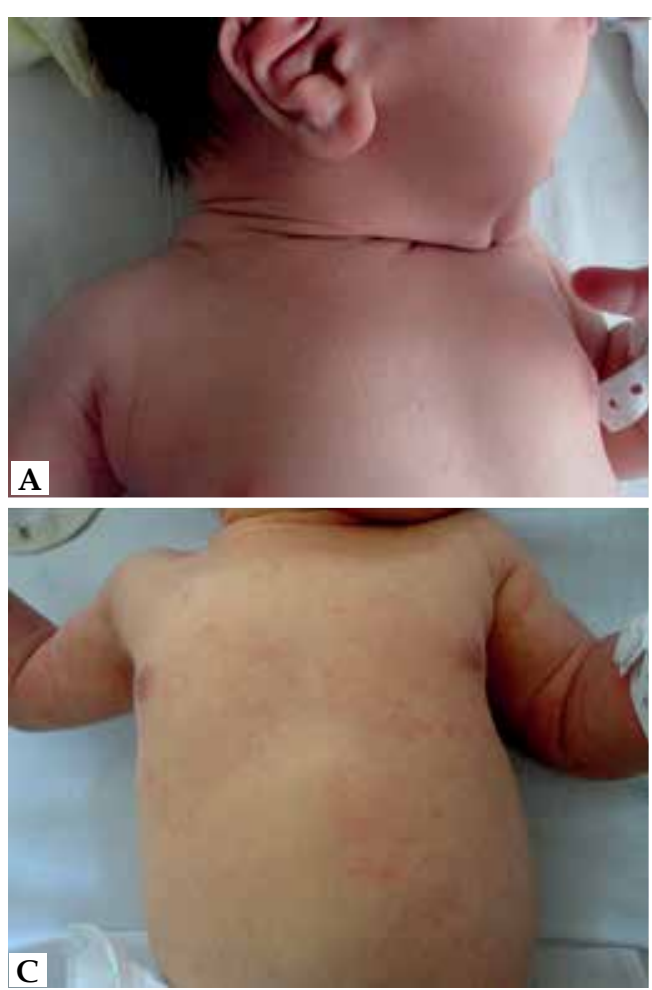
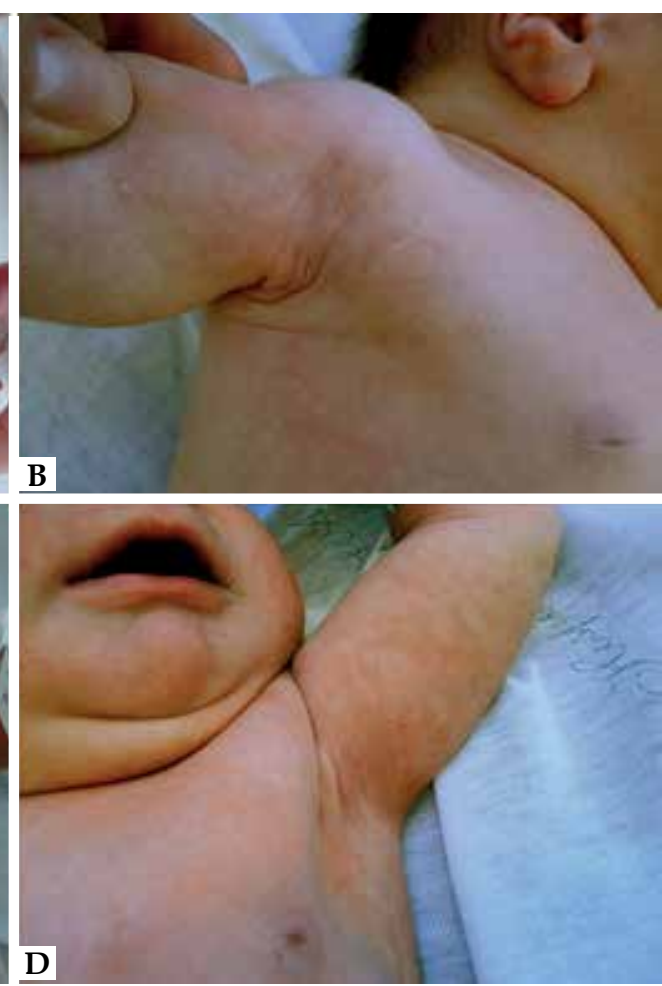

Figure 8: Miliaria. A: Miliaria crystallina: microvesicles in the neck and chest of a newborn. B and D: Miliaria pustulosa: pustules on the axillary region of a newborn. C: Miliaria rubra: erythematous papules on the trunk of an newborn 


\section{Infantile acropustulosis:}

Infantile acropustulosis (IA) is characterized by the recurrent appearance of very pruritic vesicopustules, with palmar and plantar predominance, but that can affect the back of the hands, feet, ankles, wrists and scalp. ${ }^{5}$ It usually appears between the first 2 and 12 months of life, with eruptions that last between 7 to 14 days, interspersed with periods of a few weeks of remission, and it is rare in the neonatal period. The cytological examination of the lesions shows predominance of neutrophils and histopathological examination demonstrates the presence of intraepidermal pustules with polymorphonuclear neutrophils and eosinophils. Scabies is its main differential diagnosis. ${ }^{34}$

\section{Eosinophilic pustular folliculitis:}

Eosinophilic pustular folliculitis (EPF) usually affects infants between 5 and 10 months of life..$^{35}$ It is characterized by polymorphous eruption with very pruritic vesicopustules that coalesce forming exudative and crusted plates located mainly on the scalp and less often on the face and extremities. ${ }^{5}$ Eruptions are intermittent, lasting from one to four weeks, self-limited, disappearing in several months to a few years. Microscopy shows infiltrates with eosinophils and neutrophils of perifollicular distribution on the scalp, and perivascular distribution on the skin. Blood count shows leukocytosis and eosinophilia in $70 \%$ of cases. ${ }^{32}$

\section{Scabies}

Scabies is an infectious disease that occurs when the parasite Sarcoptes scabei invades the stratum corneum. It can affect the newborn if contamination occurs soon after birth. The clinical pattern of scabies in NB is different from that observed in infants, older children and adults. In the newborn, vesicles are a frequent finding and there is a tendency to form pustules on the initial course of the infestation. ${ }^{11}$ Irritability, poor eating and little weight gain are also characteristic.

\section{CONCLUSION}

Pustulous settings are common in newborns and can be related to infections or benign skin diseases. It is important that the benign pustulosis of the neonatal period, such as erythema toxicum neonatorum, transient neonatal pustular melanosis, benign cephalic pustulosis and miliaria are recognized from the clinical setting, in order to avoid unnecessary procedures.

\section{REFERENCES}

1. Moosavi Z, Hosseini T. One-year survey of cutaneous lesions in 1000 consecutive Iranian newborns. Pediatr Dermatol. 2006;23:61-3.

2. Larralde M, Luna PC. Pustulosis neonatales estérelis. Dermatol Pediatr Latinoam. 2008;6:2-9.

3. Nikolovski J, Stamatas GN, Kollias N, Wiegand BC. Barrier function and waterholding and transport properties of infant stratum corneum are different from adult and continue to develop through the first year of life. J Invest Dermatol. 2008;128:1728-36.

4. Gokdemir G, Erdogan HK, Köşlü A, Baksu B. Cutaneous lesions in Turkish neonates born in a teaching hospital. Indian J Dermatol Venereol Leprol. 2009;75:638.

5. Ferrandiz C, Bielsa I, Ferrándiz L. Pustulosis estériles. In: Casabé STPD, Valverde RA, editors. Dermatologia Neonatal. Buenos Aires: Copyright; 2005. p. 182-86.

6. Nanda S, Reddy BS, Ramji S, Pandhi D. Analytical study of pustular eruptions in neonates. Pediatr Dermatol. 2002;19:210-5.

7. Stamatas GN, Nikolovski J, Mack MC, Kollias N. Infant skin physiology and development during the first years of life: a review of recent findings based on in vivo studies. Int J Cosmet Sci. 2011;33:17-24.

8. Stamatas GN, Nikolovski J, Luedtke MA, Kollias N, Wiegand BC. Infant skin microstructure assessed in vivo differs from adult skin in organization and at the cellular level. Pediatr Dermatol. 2010;27:125-31.

9. Eichenfield LF, Hardaway CA. Neonatal dermatology. Curr Opin Pediatr. 1999;11:471-4

10. Behne MJ, Barry NP, Hanson KM, Aronchik I, Clegg RW, Gratton E, et al. Neonatal development of the stratum corneum pH gradient: localization and mechanisms leading to emergence of optimal barrier function. J Invest Dermatol. 2003;120:998-1006.

11. Van Praag MC, Van Rooij RW, Folkers E, Spritzer R, Menke HE, Oranje AP. Diagnosis and treatment of pustular disorders in the neonate. Pediatr Dermatol. 1997;14:131-43.
12. Greco MF, Frieden L. Enfermidades vesicoampollares del recién nacido. In: Larralde M, editor. Dermatología pediátrica. Buenos Aires, Argentina: Ediciones Journal; 2010. p. 29-37.

13. Liu C, Feng J, Qu R, Zhou H, Ma H, Niu X, et al. Epidemiologic study of the predisposing factors in erythema toxicum neonatorum. Dermatology. 2005;210:269-72.

14. Chang MW, Jiang SB, Orlow SJ. Atypical erythema toxicum neonatorum of delayed onset in a term infant. Pediatr Dermatol. 1999;16:137-41.

15. Akoglu G, Ersoy Evans S, Akca T, Sahin S. An unusual presentation of erythema toxicum neonatorum: delayed onset in a preterm infant. Pediatr Dermatol. 2006;23:301-2.

16. Marchini G, Hultenby K, Nelson A, Yektaei-Karin E, Ståbi B, Lonne-Rahm S, et al. Increased expression of HMGB-1 in the skin lesions of erythema toxicum. Pediatr Dermatol. 2007;24:474-82.

17. Menni S, Boccardi D, Crosti C. Neonatal toxic erythema: clinico-epidemiologic characteristics and recent pathogenic hypothesis. Pediatr Med Chir. 2005;27:22-5.

18. Reginatto FP, De Villa DM, Muller FM, Peruzzo J, Peres LP, Steglich RB, et al. Prevalence of neonatal dermatologic findings in 3 school hospitals of Porto Alegre. J Am Acad Dermatol. 2014;70:AB148.

19. Dragomir C, Florescu L, Buhuş M. Erythema toxicum neonatorum. Rev Med Chir Soc Med Nat lasi. 2006;110:797-800.

20. Monteagudo B, Labandeira J, Cabanillas M, Acevedo A, Toribio J. Prospective study of erythema toxicum neonatorum: epidemiology and predisposing factors. Pediatr Dermatol. 2012;29:166-8.

21. Ekiz 0, Gül U, Mollamahmutoğlu L, Gönül M. Skin findings in newborns and their relationship with maternal factors: observational research. Ann Dermatol. 2013;25:1-4.

22. Boralevi F. Erythema toxicum neonatorum: still a problem in 2005 ? Dermatology. 2005;210:257-8. 
23. Yamasaki 0, Manabe K, Morimoto A, Iwatsuki K. Pustular erythema toxicum neonatorum in two siblings born to a mother with group $B$ streptococcus colonization. Eur J Dermatol. 2011;21:271-2.

24. Marchini G, Ulfgren AK, Loré K, Ståbi B, Berggren V, Lonne-Rahm S. Erythema toxicum neonatorum: an immunohistochemical analysis. Pediatr Dermatol. 2001;18:177-87

25. Marchini G, Nelson A, Edner J, Lonne-Rahm S, Stavréus-Evers A, Hultenby K. Erythema toxicum neonatorum is an innate immune response to commensal microbes penetrated into the skin of the newborn infant. Pediatr Res. 2005;58:613-6.

26. Droitcourt C, Khosrotehran K, Halaby E, Aractingi S. Maternal cells are not responsible for erythema toxicum neonatorum. Pediatr Dermatol. 2008;25:411-3.

27. Nelson A, Ulfgren AK, Edner J, Ståbi B, Brismar H, Hultenby K, et al. Urticaria Neonatorum: accumulation of tryptase-expressing mast cells in the skin lesions of newborns with Erythema Toxicum. Pediatr Allergy Immunol. 2007;18:652-8.

28. Marchini G, Ståbi B, Kankes K, Lonne-Rahm S, Østergaard M, Nielsen S. AQP1 and $A Q P 3$, psoriasin, and nitric oxide synthases 1-3 are inflammatory mediators in erythema toxicum neonatorum. Pediatr Dermatol. 2003;20:377-84.

29. González Echeverría F, Martínez Rodríguez J, Ancín Chandía T, Córdoba Iturriaga A. Is neonatal toxic erythema a risk factor in the development of allergy in childhood? An Esp Pediatr. 1997;47:515-20.

30. Laude TA. Approach to dermatologic disorders in black children. Semin Dermatol. 1995;14:15-20.

31. O'Connor NR, McLaughlin MR, Ham P. Newborn skin: Part I. Common rashes. Am Fam Physician. 2008;77:47-52.

32. Sergay A, Schachner L. Pustulosis. In: Casabé STPD, Valverde RA, editors. Dermatologia Neonatal. Buenos Aires: Copyright; 2005. p. 275-82.

33. Ayhan M, Sancak B, Karaduman A, Arikan S, Sahin S. Colonization of neonate skin by Malassezia species: relationship with neonatal cephalic pustulosis. J Am Acad Dermatol. 2007;57:1012-8.

34. Newton JA, Salisbury J, Marsden A, McGibbon DH. Acropustulosis of infancy. $\mathrm{Br}$ J Dermatol. 1986;115:735-9.

35. Buckley DA, Munn SE, Higgins EM. Neonatal eosinophilic pustular folliculitis. Clin Exp Dermatol. 2001;26:251-5.
MAILING ADDRESS:

Flávia Pereira Reginatto

Rua Ramiro Barcelos, 2350

Santa Cecília

90035-903 - Porto Alegre - RS

Brasil

E-mail: flaviareginatto@ufrgs.br

How to cite this article: Reginatto FP, De Villa D, Cestari TF. Benign skin disease with pustules in the newborn. An Bras Dermatol. 2016;91(2):124-34. 


\section{Questions}

1) Facing the newborn with pustules, some maternal diseases should be discarded, such as:

a) Vulvovaginal candidiasis and syphilis

b) Genital herpes

c) Scabies

d) All of the above

2) Regarding additional tests required in the case of diagnostic uncertainty in newborns with skin pustule, check the incorrect alternative:

a) Direct examination of scales clarification with potassium hydroxide allows identify fungal elements and is useful for the detection of dermatophytosis and other fungal infections by Malassezia or Candida spp genres.

b) The Tzanck smear informs about the presence of multinucleated cells and inclusion bodies is suggestive of herpes infection.

c) Skin biopsy is the first examination to be performed, and it is essential in the presence of pustules on the skin of the newborn.

d) In specific cases, syphilis serology, culture of the blisters content or skin biopsy should be performed.

3) What is the main supplementary examination to be performed in atypical cases of neonatal benign pustuloses (NBP) and its respective finding?

a) Tzanck smear, which informs about the presence of multinucleated cells and inclusion bodies suggestive of herpes infection, in erythema toxicum neonatorum shows a predominance of eosinophils, and in transient neonatal pustular melanosis, a predominance of neutrophils.

b) Skin biopsy, which shows subcorneal pustule with perifollicular inflammatory infiltrate in cases of erythema toxicum neonatorum; inflammatory infiltrate with predominance of polymorphonuclear neutrophils in cases of TNPM; and subcorneal pustule with predominance of lymphocytes in cases of benign cephalic pustulosis.

c) Quantitative maternal Venereal Disease Research Laboratory (VDRL) and, in the newborn, Fluorescent treponemal antibody absortion test (FTA-Abs).

d) Scraping of the lesion and potassium chloride examination to discard dermatophytosis and congenital or neonatal candidiasis.

4) Regarding functional differences between newborn and adult skin, check the correct alternative:

a) Despite the NB skin is often characterized as delicate and fragile; there are no functional differences between the newborn and adult skin.

b) The newborn skin has functional differences compared with adult skin, but these cannot be attributed to differences in the microstructure of the skin.

c) Besides being $40 \%$ to $60 \%$ thinner than an adult's skin, the NB skin presents lower transepidermal water loss and delay in sweat response.

d) The newborn skin has a higher transepidermal water loss and delay in sweat response.

5) Regarding the maturation of intrauterine human skin is correct to say:

a) The barrier function of human skin starts to develop in utero with the stratification of the epidermis during the second trimester and is incomplete at birth, in the fullterm.

b) The barrier function of human skin begins to develop in utero with the stratification of the epidermis during the first trimester of pregnancy and it is believed to be complete by 34 weeks of gestation.

c) The formation of vernix caseosa occurs in the second trimester and contributes to the final stage of maturation of the epidermal barrier.

d) As the epidermal barrier function by baseline permeability is not complete at birth, there is a high risk of infections, dermatitis and percutaneous absorption of toxic agents.

6) What are the most common pustulosis in the neonatal period?

a) The erythema toxicum neonatorum, the transient neonatal pustular melanosis and the benign cephalic pustulosis.

b) The erythema toxicum neonatorum, the miliaria rubra and the transient neonatal pustular melanosis.

c) The transient neonatal pustular melanosis, the infantile acropustulosis and scabies.

d) The erythema toxicum neonatorum, miliaria profunda and Langerhans cell histiocytosis.

7) About erythema toxicum neonatorum, check the incorrect alternative:

a) It is characterized by small erythematous papules, pustules and vesicles affecting the trunk, face, and extremities.

b) It is an inflammatory skin reaction, also called neonatal allergic erythema or neonatal erythema.

c) Despite pustules of the erythema toxicum neonatorum are sterile, the main identified pathogen is Staphilococos aureus.

d) Lesions usually appear on the second day of life and regress in 5 to 14 days; atypical settings may have a later onset. 
8) What is the prevalence of erythema toxicum neonatorum estimated for our population?
a) $3 \%$ to $4 \%$
b) $10 \%$ to $15 \%$
c) $21 \%$ to $23 \%$
d) Approximately $90 \%$

9. The following statements about the erythema toxicum neonatorum are true:

a) The etiology of erythema toxicum neonatorum is well established: lesions occur as a reaction to Staphilococos aureus toxin.

b) Its etiology remains unknown, but recent studies have shown activation of immune cells in the ETN lesions, suggesting an inflammatory reaction of the skin to microbial colonization that occurs at birth.

c) It is more common in female newborns.

d) It occurs more frequently in premature newborns compared to full-term newborns.

10. What alternative best describes the characteristic lesions of erythema toxicum neonatorum:

a) Follicular pustules that mainly affects the palms and soles.

b) Vesicles and pustules that develop into peripheral scaling and leave persistent hyperpigmented macule.

c) Papules and pustules with an erythematous halo that regress leaving anetodermic scars.

d) Pustules surrounded by an erythematous halo of about 1 to $2 \mathrm{~cm}$ affecting mainly the trunk, limbs and face of the newborn.

11. Lesions that are usually present at birth and are characterized by flaccid and superficial pustules that rupture easily forming a colarette of scales that evolve into hyperpigmented macules of residual character, corresponds to:

a) Erythema toxicum neonatorum

b) Transient neonatal pustular melanosis

c) Benign cephalic pustulosis

d) Eosinophilic pustular folliculitis

12. As for transient neonatal pustular melanosis it is correct to say:

a) All areas of the body can be affected, but palms and soles are usually spared.

b) Lesions usually are not present at birth.

c) There are cases of intrauterine evolution that leave residual hyperpigmented macules at birth.

d) It is more common in Caucasian newborns.

13. Regarding the cytological examination of transient neonatal pustular melanosis lesions, it is true:

a) The cytological examination of pustules shows polymorphonuclear neutrophils.

b) The cytological examination of the pustules shows pre- dominance of eosinophils.

c) There is a predominance of lymphocytes.

d) As in anatomopathological examination, cytology shows mixed inflammatory infiltrate.

14. When differentiating erythema toxicum neonatorum from transient neonatal pustular melanosis, check the correct alternative:

a) The etiological mechanisms of ETN and TNPM are well established and are the same.

b) It is likely that TNPM corresponds to a variance of ETN, because there are many cases in the literature that the same newborn presents clinical and histological findings of ETN and TNPM.

c) The clinical difference between TNPM and ETN is always clear, and there are no cases where ETN is present at birth or where the clinical finding is of TNPM, but the histology shows the characteristic findings of ETN.

d) ETN is more common in African-American newborns and TNPM is usually more common in Caucasian newborns.

15. Check the correct alternative regarding benign cephalic pustulosis:

a) It presents a benign and self-limited course.

b) The dermatosis is characterized by multiple inflammatory papules and pustules on the face and scalp that usually begin between 5 days and 3 weeks of age.

c) The direct examination of smear of the pustule, clarified with potassium hydroxide, can show mycotic elements and culture can show Malassezia synpodialis and, less frequently, M. furfur or M. Globosa.

d) All alternatives are correct.

16) Miliaria rubra is characterized by:

a) Numerous erythematous papules or pruritic papular vesicles grouped in areas that are not under occlusion.

b) Small vesicles on healthy skin, especially on the face, neck and trunk.

c) Small erythematous papules caused by obstruction of the eccrine sweat gland duct slightly deeper than in $\mathrm{MC}$, with sweat retention in the epidermis.

d) All alternatives are correct.

17) The differential diagnosis of benign neonatal pustulosis is conducted with:

a) Molluscum contagiosum, erythema toxicum neonatorum and eosinophilic folliculitis.

b) Scabies, neonatal herpes and neonatal abscess.

c) Milia cyst, sebaceous gland hyperplasia and neonatal acne.

d) Infantile acropustulosis, eosinophilic pustular folliculitis and neonatal scabies. 
18) Infantile acropustulosis is characterized by:

a) Recurrent appearance of very pruritic vesicopustules with palmar and plantar dominance, but it also can affect the back of the hands, feet, ankles, wrists and scalp

b) Vesicopustules that usually appear in the first days of life.

c) Eruptions lasting 7 to 14 days, interspersed with periods of remission of several weeks, and common in the neonatal period.

d) Cytology examination of the lesions shows predominance of neutrophils and in histopathological examination it's possible to observe the presence of intraepidermal pustules with atypical lymphocytes.

19) The eosinophilic pustular folliculitis usually affects infants between 5 and 10 months of life. Lesions are characterized by:

a) Polymorphous eruption with very pruritic vesico-pustules that converge forming exudative and crusted plaques located mainly on the scalp and less often on the face and extremities.

b) The eruptions are intermittent, during from one to four weeks, self-limited, resolving in several months to a few years.

c) Microscopy shows infiltrated with eosinophils and perifollicular distribution of neutrophils in the scalp, and perivascular distribution when located in the skin.

d) All the alternatives are correct.

\section{0) Check the right alternative:}

a) Benign neonatal pustulosis rarely occur.

b) Benign neonatal pustulosis often occur, mainly due to erythema toxicum neonatorum and to transient neonatal pustular melanosis.

c) It is always necessary to perform additional tests for the diagnosis of various benign neonatal pustuloses.

d) Genodermatosis or other conditions that can present systemic involvement are not part of the differential diagnosis.

Answer key
Psoriasis: new comorbidities 2016;91(1):08-16.

\section{Papers}

Information for all members: The EMC-D questionnaire is now available at the homepage of the Brazilian Annals of Dermatology: www.anaisdedermatologia.org.br. The deadline for completing the questionnaire is 30 days from the date of online publication. 